\title{
Superparasitism, immune response and optimum progeny yield in the gregarious parasitoid Palmistichus elaeisis
}

\author{
Kleber de S Pereira, ${ }^{a}$ Nelsa Maria P Guedes, ${ }^{\text {a,b }}$ José E Serrão, ${ }^{c}$ \\ José C Zanuncio ${ }^{\mathrm{a}}$ and Raul Narciso C Guedes ${ }^{\mathrm{a}^{*}}$
}

\begin{abstract}
BACKGROUND: The subsequent deposition of an egg clutch by a female parasitoid into a host already parasitised either by itself or a conspecific (i.e. superparasitism) is a counterintuitive adaptive strategy, particularly considering the female parasitoid's ability to recognise the parasitised hosts. Such a scenario suggests that the adaptive value of superparasitism depends on the number of clutches laid in the same host, with consequences for parasitoid progeny yield. Here, we tested whether such is the case for the gregarious parasitoid Palmistichus elaeisis and explored its underlying basis.

RESULTS: Allowing female parasitoids to lay multiple egg clutches in a single melonworm host pupa, parasitoid progeny and fitness exhibited a peak or optimum at three egg clutches laid per host pupa. In addition, haemocyte count, encapsulation and melanisation decreased with the number of egg clutches laid per host pupa.

DISCUSSION: An optimum number of three clutches laid per host pupa was detected for $P$. elaeisis. As immune response via haemocyte production, encapsulation and melanisation decreased with the number of clutches laid per host, the higher parasitoid yield and fitness observed is the likely consequence of a compromised immune response coupled with an accommodative (i.e. scramble) larval competitive strategy allowing enough resources for optimum balance of parasitoid number and quality produced.
\end{abstract}

(c) 2017 Society of Chemical Industry

Keywords: larval competition; intrinsic parasitoid competition; idiobiont parasitoid; immunity; haemocyte; encapsulation

\section{INTRODUCTION}

Resource competition is a determinant of animal behaviour and life history where two alternative (intraspecific) strategies may take place - contest and scramble competition. ${ }^{1-3}$ While in contest competition there is direct interference among competing individuals, with the successful competitor securing much of the governing resources needed for its development and reproduction, in scramble competition there is resource sharing and accommodation of all competitors, favouring their survival, but at the expense of their individual fitness. ${ }^{4-6}$ Competition is a particular problem for insect endoparasitoids, the larval stages of which are spent within a single host, where intrinsic competition takes place (i.e. among immature parasitoids in a host), with potential implications for their rearing and use as bicontrol agents in pest management programmes. $^{7-9}$

Most endoparasitoids seem able to recognise and reject parasitised hosts, preventing potential larval competition. ${ }^{1-13}$ This is commonly observed among solitary parasitoids, where only a single larva is able to complete its development within a host and direct larval interference (i.e. aggression) is expected, ${ }^{14,15}$ as also observed in some stored-grain beetles. ${ }^{16-18}$ Nonetheless, gregarious parasitoids provide a different context in which two or more offspring complete development in a single host, favouring a scramble (or accommodation) type of competition. ${ }^{19,20}$
However, even among gregarious parasitoids, the rejection of already parasitised hosts is expected, favouring progeny development and survival, but several species do superparasitise their hosts. ${ }^{10-12,21}$

Superparasitism takes place when a female parasitoid lays a clutch of eggs on or in a host already parasitised by the female itself (i.e. self-superparsitism) or a conspecific. ${ }^{10,19}$ This phenomenon is counterintuitive and was considered maladaptive until eventually recognised as adaptive in some situations by the $1980 \mathrm{~s}^{10}$ Curiously, superparasitism is frequent in several hymenopteran species and remains a study challenge where the host and the parasitoid need to be considered, as well as the underlying mechanisms involved..$^{9,20,21}$ Therefore, not only is the output of superparasitism important but also the process involved. For instance,

\footnotetext{
Correspondence to: RNC Guedes, Departamento de Entomologia, Universidade Federal de Viçosa,Viçosa, MG 36570-900, Brazil.E-mail: guedes@ufv.br

a Departamento de Entomologia, Universidade Federal de Viçosa, Viçosa, MG, Brazil

b ENTO $^{+}$Soluções \& Pesquisa, CENTEV-UFV, Viçosa, MG, Brazil

c Departamento de Biologia Geral, Universidade Federal de Viçosa, Viçosa, MG,
} Brazil 
although avoiding superparasitism will potentially benefit the siblings from a egg clutch, host (or resource) use likely improves under such conditions, suggesting that superparasitism should prevail with host scarcity. ${ }^{9,20,21}$ Nonetheless, multiple ovipositions may take place in different species without apparent host scarcity, indicating a more complex scenario ${ }^{21,22}$ and the possibility of a density-dependent optimum number of egg clutches laid, allowing for maximum parasitoid larval fitness and host use.

Infanticide and haemocyte-mediated encapsulation are two non-exclusive alternative strategies that may favour superparasitism. ${ }^{23,24}$ Infanticide (including ovicide) takes place when the superparasitising female increases the likelihood of her offspring's survival by killing at least some individuals of the previous egg clutch laid in the same host..11,14 Regarding encapsulation, the immune response of the parasitoid host is also potentially compromised, with superparasitism favouring this outcome because multiple egg clutches within the host are likely to overwhelm the host's defences. ${ }^{19,22}$

Both phenomena, infanticide and encapsulation, may take place simultaneously, enhancing the odds in favour of superparasitism, although the development of mixed broods within a host may allow for indirect benefits and/or brother-sister matings advantageous for some species, ${ }^{12}$ and still benefit from compromising the host immune response. ${ }^{22}$ However, the host immune response and particularly the cellular immune response (or haemocyte-mediated encapsulation) have been characterised in few insect species other than traditional model insects, and merit further attention. ${ }^{25,26}$ The same argument is valid for the larva-competition-oriented studies of superparasitism, where the process of competition is usually inferred from the outcome of competition without direct assessment, ${ }^{11,27-31}$ which may result in misleading conclusions, as observed in grain weevils. ${ }^{18}$

The gregarious endoparasitoid Palmistichus elaeisis Delvare \& LaSalle (Hymenoptera: Eulophidae) provides an opportunity to assess larval competition with its consequences and underlying mechanisms. This is so because this parasitoid is a generalist species with potential economic importance as a biocontrol agent of several arthropod pest species, including the melonworm Diaphania hyalinata (L.) (Lepidoptera: Crambidae), the tomato pinworm Tuta absoluta (Meyrick) (Lepidoptera: Gelechiidae) and the sugarcane borer Diatraea saccharalis (F.), among others. ${ }^{22,32,33}$ Furthermore, the species undergo superparasitism, particularly self-superparasitism, but also conspecific superparasitism overcoming its host cellular immune response. ${ }^{22}$

Here, we investigated the mechanism of larval competition with increasing levels of self-superparasitism of melonworm pupae by $P$. elaeisis, using digital X-ray imaging to follow the parasitoid development within its host as a direct method of investigation, and also using the outcome of superparasitism for indirect assessment of the process of competition and the fitness of the progeny produced. The strategy potentially allows the recognition of the eventual optimum level of superparasitism, measured as the number of ovipositions per host (or number of egg clutches laid per host), which was one of the aims of our study, which also attempted to recognise the potential density-dependent relationship between the level of superparasitism and the host immune response. Therefore, the immune response of the parasitised host pupae was also recorded under increasing superparasitism to recognise its potential relevance in determining the optimum level of parasitism, if any density-dependent relationship exists in such a phenomenon. A scramble type of competition was expected, with the accommodation of multiple larvae within a single host pupa, based on previous reports of frequent superparasitism in this species. ${ }^{22,31-33}$ However, we also expected an optimum level of superparasitism, as detected in grain beetles ${ }^{16,18,34}$ but not yet explored in endoparasitoids in the context of larval competition and host immune response.

\section{MATERIALS AND METHODS}

\subsection{Host insect}

The pupae of melonworm were from a laboratory colony maintained on chayote leaves [Sechium edule (Jacq.) Sw.], which were daily provided until the prepupal stage in $3 \mathrm{~L}$ plastic containers with a perforated lid covered with organza tissue. The prepupae were transferred to clean $3 \mathrm{~L}$ plastic containers lined with paper towel until eventual pupation, and then the pupae were gathered and transferred to wooden-framed cages of organza $(33 \times 33 \times 33 \mathrm{~cm})$ until adult emergence. Sucrose solution $(60 \mathrm{~g}$ sucrose, $10.5 \mathrm{~g}$ honey, $1.05 \mathrm{~g}$ nipagin and ascorbic acid diluted in $1.05 \mathrm{~L}$ of water) was provided in imbibed cotton balls placed over a petri dish in each cage. ${ }^{35}$ Pumpkin leaves were placed within the cage for the adult females of the melonworm to lay their eggs, which were subsequently collected and placed in $3 \mathrm{~L}$ plastic containers for rearing. ${ }^{36}$ The insects were reared in a controlled environment room at $25 \pm 2{ }^{\circ} \mathrm{C}, 70 \pm 10 \%$ relative humidity and a 12:12 h (L:D) photoperiod.

\subsection{Parasitoid}

The parasitoids were also from a laboratory colony maintained at $25 \pm 2{ }^{\circ} \mathrm{C}, 70 \pm 10 \%$ relative humidity and a $14: 10 \mathrm{~h}(\mathrm{~L}: \mathrm{D})$ photoperiod, the same conditions in which the entire study was carried out. The parasitoids were reared in glass tubes $(14 \mathrm{~cm}$ length $\times 2.2 \mathrm{~cm}$ diameter) with a drop of honey provided on a cotton ball. ${ }^{37}$ Females and males of $P$. elaeisis were paired between 24 and $36 \mathrm{~h}$ after emergence, and mealworm pupae ( $24-72 \mathrm{~h}$ old) were individualised with six parasitoid females each; the emerging adult parasitoids were subsequently used in the study.

\subsection{Parasitoid larval competition}

Each melonworm pupa ( $24 \mathrm{~h}$ old; $114 \pm 0.08 \mathrm{mg}$ ) was exposed to one $(n=34)$, two $(n=27)$, three $(n=27)$, four $(n=24)$ or five ovipositions $(n=21)$ by the same female parasitoid of P. elaeisis $(76-96 \mathrm{~h}$ old, when their oocytes are mature and suitable for egg laying). ${ }^{22,23}$ This was done on plastic cylinder arenas $(2.2 \mathrm{~cm}$ diameter $\times 1.8 \mathrm{~cm}$ height) after sexing the females using morphological characteristics of their abdomen. ${ }^{38}$ The parasitism was monitored through recording, using a camera (charge coupled device, CCD) coupled to a stereomicroscope (Stemi 2000; Zeiss, Göttingen, Germany). The parasitised pupae were individualised in glass tubes $(14 \mathrm{~cm}$ length $\times 2.2 \mathrm{~cm}$ diameter) and maintained under controlled conditions, as previously detailed for parasitoids.

The parasitoid development within each host was directly followed through daily inspections of the host pupae using a LX-60 specimen radiography system equipped with a digital camera (Faxitron X-Ray Corp., Wheeling, IL). Therefore, the locations and eventual interaction among larvae within the host, as well as their developmental stage and overall health condition, were digitally recorded throughout their development. Parasitoid developmental time, emergence, sex and body mass were all recorded, and the progeny fitness was estimated as the biomass of progeny produced per host pupa. ${ }^{3,6,39}$ As fecundity and longevity are associated with body mass and larval survival, ${ }^{20}$ and adult body mass is 
affected by larval competition, these parameters are included in measures of larval fitness. This was achieved by determining the parasitoid biomass $(\mathrm{mg})$ produced per host, generating larval fitness curves. ${ }^{6}$

\subsection{Host immune response}

Host immune response was recorded for all levels of superparasitism and included haemocyte counts and determination of the rates of encapsulation and melanisation, as detailed below.

\subsubsection{Haemocyte count and characterisation}

Unparasitised and parasitised pupae of the same age $(24 \mathrm{~h}$ after parasitism) were rinsed with sodium hypochloride solution (1\%) for $5 \mathrm{~s}$ and subsequently with distilled water. Host insect haemolymph $(4 \mu \mathrm{L})$ was collected with micropipettes from a small head incision and transferred to a $20 \mu \mathrm{L}$ solution of anticoagulant $\left(98 \mathrm{~mm}\right.$ of $\mathrm{NaOH}, 186 \mathrm{~mm}$ of $\mathrm{NaCl}, 17 \mathrm{~mm}$ of EDTA- $\mathrm{Na}_{2}$ and $41 \mathrm{~mm}$ of citric acid; $\mathrm{pH} 4.5$ ) to prevent haemocyte aggregation. ${ }^{27}$ The haemolymph samples were stained ( $4 \mu \mathrm{L}$ of Giemsa), and two $8 \mu \mathrm{L}$ aliquots of this solution were added at each side of a Neubauer haemocytometer with a $40 \times$ objective lens (Bright-Line; New Optics, Gyeibggi-do, South Korea) to recognise and quantify the haemocyte types.22,27,40 Ten host pupae at each level of superparasitism were subject to such characterisation and quantification.

\subsubsection{Encapsulation and melanisation}

The encapsulation defence response by the host pupa was assessed through the haemocyte adherence to nylon filaments $(2 \times 0.2 \mathrm{~mm})$ implanted into individuals subjected to the range of parasitoid ovipositions scrutinised. The nylon filaments were initially sterilised with sodium hypochloride (1\%) and subsequently washed with distilled water before being implanted into the melonworm pupae ( $24 \mathrm{~h}$ old; $109 \pm 0.01 \mathrm{mg}$ of fresh body mass). Between ten and 13 pupae at each level of superparasitism (1-5 parasitoid ovipositions) were implanted with nylon filaments. Their immune response was recorded $48 \mathrm{~h}$ after implant insertion while removing them from the pupae under dissection. The nylon implants removed were mounted on slides and digitally photographed with a AxioCam MRc5 camera coupled to a stereomicroscope (Zeiss) and processed with AxioVision software (Zeiss).

The rate of encapsulation was determined on the basis of the haemocyte cell layer covering the implanted nylon filaments and estimating the encapsulated area of the implant. ${ }^{22,41,42}$ The digitalised figures of the nylon implants were reversed to greyscale with a range variation from 0 (black) to 255 (white) to determine the rate of melanisation, the average level of which within the greyscale was determined using ImageJ 1.48 software (US National Institutes of Health, http://imagej.nih.gov/ij/download.html). The values were standardised by the darkest value obtained in the implants after adjustment by extracting the background value. ${ }^{22}$

\subsection{Statistical analyses}

Parasitoid survival results were subjected to survival analyses using Kaplan-Meier estimators (PROC LIFETEST, SAS software; SAS Institute, Cary, NC). A (partial) canonical correlation analysis was performed to test the contribution of each haemocyte type to the total haemocyte count, using the CANCORR procedure from SAS (SAS Institute). All of the remaining results

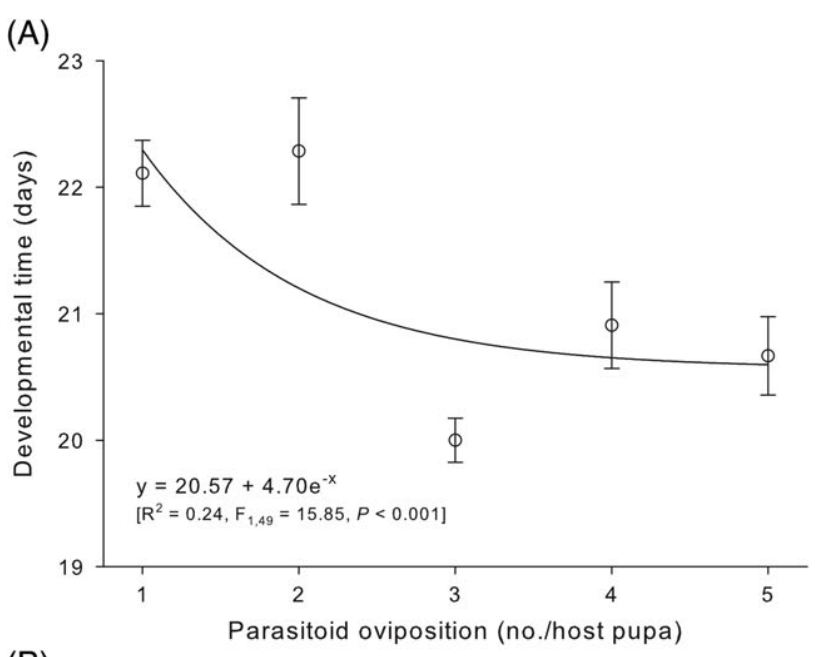

(B)

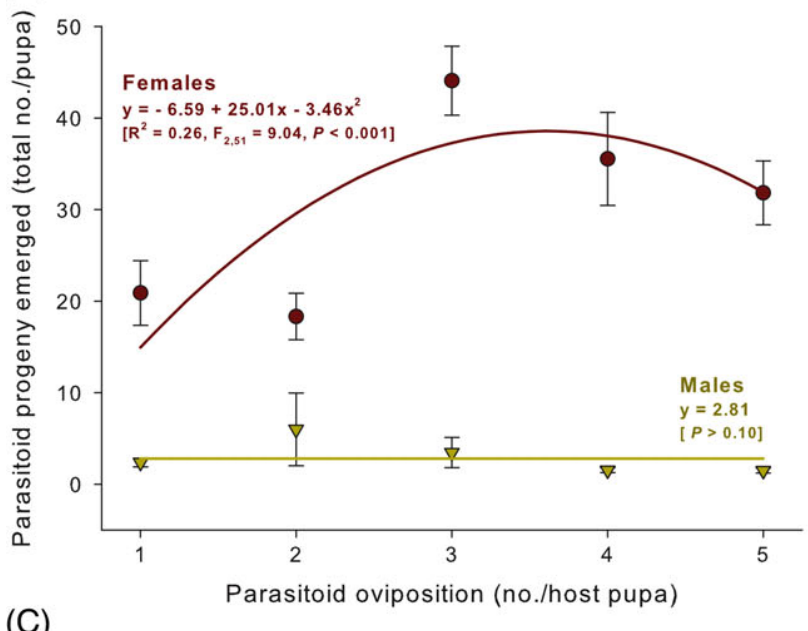

(C)

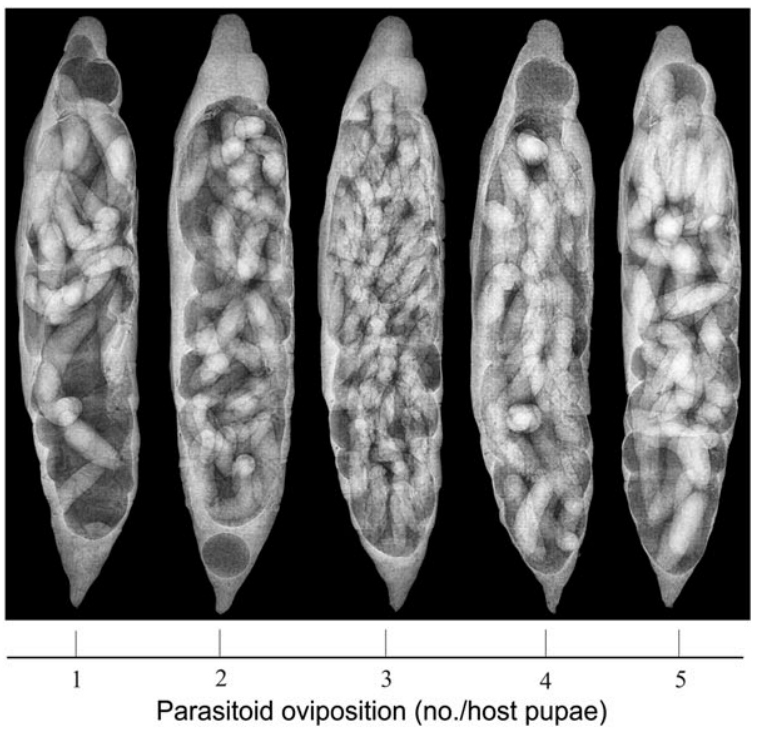

Figure 1. Developmental time $(A)$, total progeny emerged per host pupa (B) and sequential X-ray digital images (C) showing a representative sequence of developing parasitoid larvae of $P$. elaeisis within the same host pupa of the melonworm $D$. hyalinata. Each symbol in plots $(A)$ and $(B)$ represents the mean values of 24-34 replicates (i.e. pupae), and the vertical bars indicate the standard error of the means. 
(A)

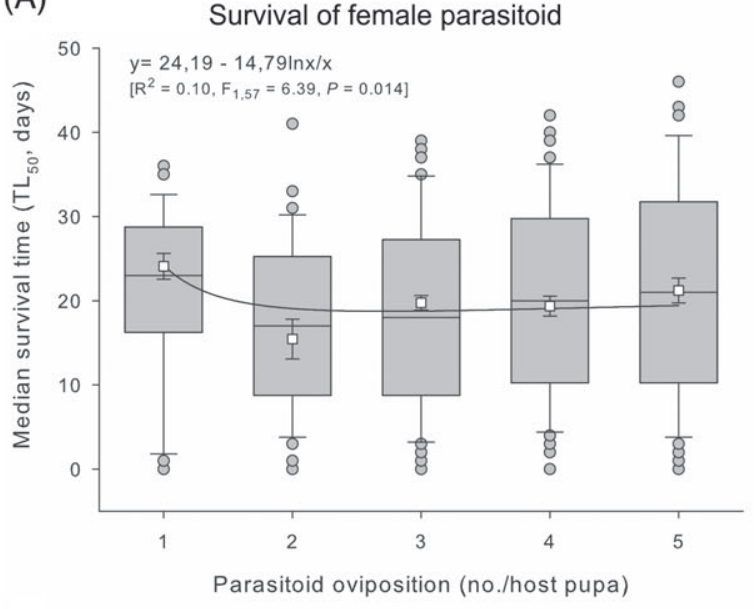

(B) Survival of male parasitoid

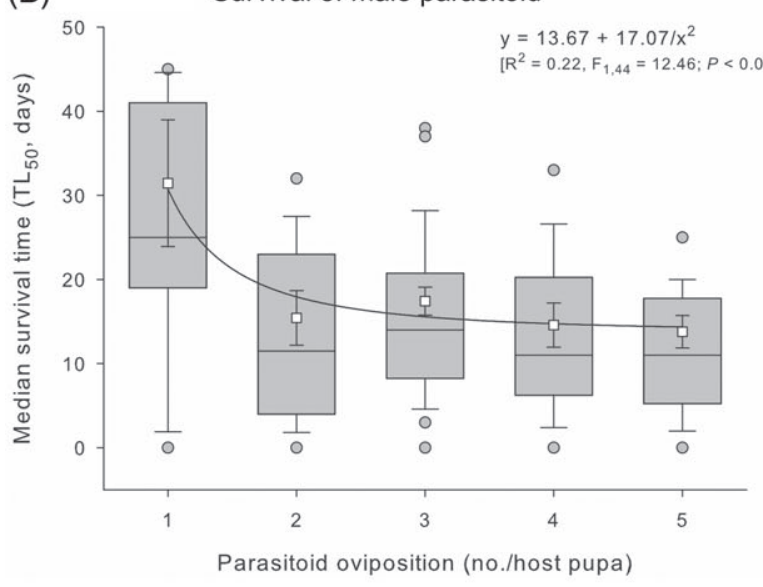

(C)

Parasitoid larva fitness curve

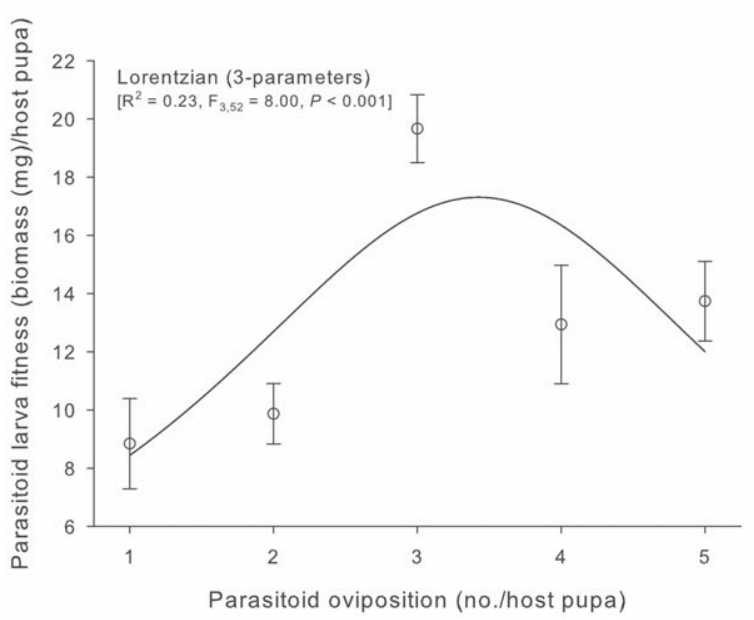

Figure 2. Median survival time $\left(\mathrm{TL}_{50}\right)$ of female $(\mathrm{A})$ and male (B) parasitoids, and larva fitness curves $(C)$ of the gregarious hymenopteran parasitoid $P$. elaeisis reared at increasing levels of superparasitism in pupae of the melonworm $D$. hyalinata. Box plots (A, B) indicate the range of data dispersion (lower and upper quartiles and extreme values), median and outliers (symbols). Each symbol in (C) represents the mean values of 24-34 replicates (i.e. pupae), and the vertical bars indicate the standard error of the means.

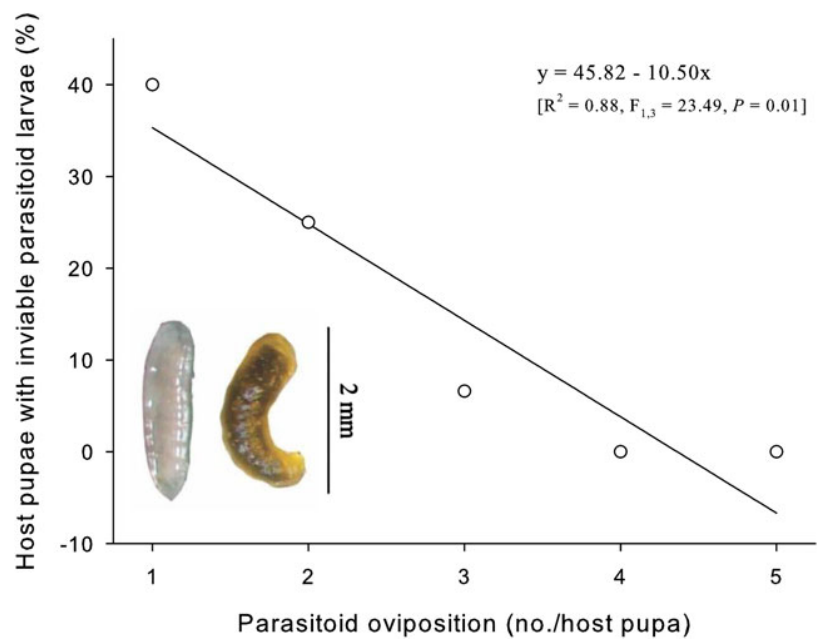

Figure 3. Host pupae of the melonworm $D$. hyalinata containing inviable parasitoids (\%) of the gregarious species $P$. elaeisis reared at increasing levels of superparasitism. The insets are representative pictures of a healthy and an inviable larva of the parasitoid P. elaeises. Each symbol represents the observed data points used in the regression estimate.

obtained were subjected to regression analysis, with the number of parasitoid ovipositions as the independent variable using the curve-fitting procedure from TableCurve 2D (Systat, San Jose, $C A)$; the significant regression models $(P<0.05)$ were tested from the simplest (linear and quadratic) to more complex peak models, and model selection was based on parsimony, high $F$-values (and mean squares) and steep increases in $R^{2}$ with model complexity.

\section{RESULTS}

\subsection{Parasitoid larval competition}

The developmental time of the parasitoid larvae varied significantly with the number of parasitoid egg clutches laid in the host pupae, exponentially decreasing with the number of ovipositions, reaching a plateau around three parasitoid ovipositions per pupa (Fig. 1A). Parasitoid female progeny emergence also varied with level of superparasitism, reaching a peak of female emergence at around three ovipositions per pupa (Fig. 1B). Curiously though, male parasitoid emergence was not affected by the level of superparasitism (Fig. 1B), and the female-biased sex ratio in this parasitoid species also remained unaffected by parasitoid load (number of females/number in total $=0.93 \pm 0.02 ; F_{1,55}=3.11, P=0.08$ ). The $X$-ray imaging analyses confirmed these results, indicating a larger number of developing parasitoids with three ovipositions per pupa and a quicker development at the higher levels of superparasitism. At these high levels of superparasitism, the parasitoid pupa is already visible within the host, unlike at lower numbers of ovipositions per host pupa (i.e. <3) (Fig. 1C).

The level of superparasitism also negatively affected parasitoid survival, with median survival times $\left(\mathrm{TL}_{50}\right)$ successfully estimated through survival analysis $(P<0.01)$ and exhibiting extended survival with a sole oviposition per pupa, both for female (Fig. 2A) and male (Fig. 2B) parasitoid progenies. The individual body mass of the emerging adult female and male parasitoids was not significantly affected by the level of superparasitism $(P<0.05)$, but female body mass was always higher than that of the male parasitoids (female: $0.42 \pm 0.001 \mathrm{mg}$; male: $0.17 \pm 0.004 \mathrm{mg}$ ). The parasitoid progeny biomass produced per pupa at each level of 
superparasitism provided a bell-shaped curve exhibiting a peak in parasitoid progeny yield at around three ovipositions per host pupa (Fig. 2C), following a trend similar to that obtained with female progeny emergence.

\subsection{Host immune response}

Inviability of parasitoid larva owing to the host immune response was also affected by the level of superparasitism, with a linear decrease in inviability with an increasing number of parasitoid egg clutches laid per pupa (Fig. 3). The host immune response did not prevent pupal death, but it did compromise parasitoid emergence by also killing the developing parasitoid progeny within the host pupa, as illustrated in the sequential X-ray images in Fig. 4. The cellular or haemocyte-mediated encapsulation of the developing parasitoids was also recorded for the melonworm pupa-P. elaeisis system.

The level of superparasitism linearly compromised the total haemocyte count in the host pupa (Fig. 5A). Five different haemocyte types were observed - granulocytes, oenocytes, plasmatocytes, prohaemocytes and spherulocytes. All of these haemocyte types were correlated with the total haemocyte count using (partial) canonical correlation $(r=0.99, P<0.001)$, with the highest contributions from oenocytes and prohaemocytes, but with a significant contribution from all types (Table 1 and Fig. 5B).

Encapsulation and melanisation were clearly observed in the implanted nylon filaments (Fig. 6A). Haemocyte adherence and aggregation in the nylon filaments, leading to encapsulation, was negatively affected by the level of superparasitism, following a linear trend (Fig. 6B). Melanisation by the host pupa was also compromised by the level of superparasitism, although an exponential rather than a linear trend was observed, with the melanisation decline accentuated at three ovipositions per pupa (Fig. 6C).

\section{DISCUSSION}

Superparasitism and particularly self-superparasitism are currently recognised as a potentially adaptive strategy frequently occurring among hymenopteran parasitoids, with potential consequences for biological control, and thus for insect pest management. ${ }^{9,10,20}$ Curiously, the mechanism of larval competition in such species and the potential fitness consequences of increasing superparasitism remain poorly investigated, although they are potentially important for optimising the mass rearing and field use of the biocontrol species. They were the target of our study, where scramble competition among parasitoid larvae was expected, based on the incidence of superparasitism in P. elaeisis. $22,32,33$ We suggested the potential existence of an optimum level of superparasitism, which had not yet been explored in endoparasitoids in the context of larval competition and host immune response. Our findings provide support for these stated expectations.

Increasing levels of superparasitism of melonworm pupae by $P$. elaeisis are associated with decreased larval developmental time and (female and male) longevity, which suggests a scramble strategy of larval competition, with larval accommodation within the host without aggressive interference among them. ${ }^{3,6,17,18}$ In contrast, the level of superparasitism did not affect male and female (fresh) body mass, nor the highly female-biased sex ratio and male emergence, which would also be expected under scramble competition. ${ }^{6,18}$ Nonetheless, males are not as frequent within this parasitoid species and exhibit lower body mass, indicating only a minor contribution for the parasitoid biomass produced per parasitised pupa. Therefore, as the body mass was not substantially

\section{(A) \\ Normal (unparasitized) pupa development}

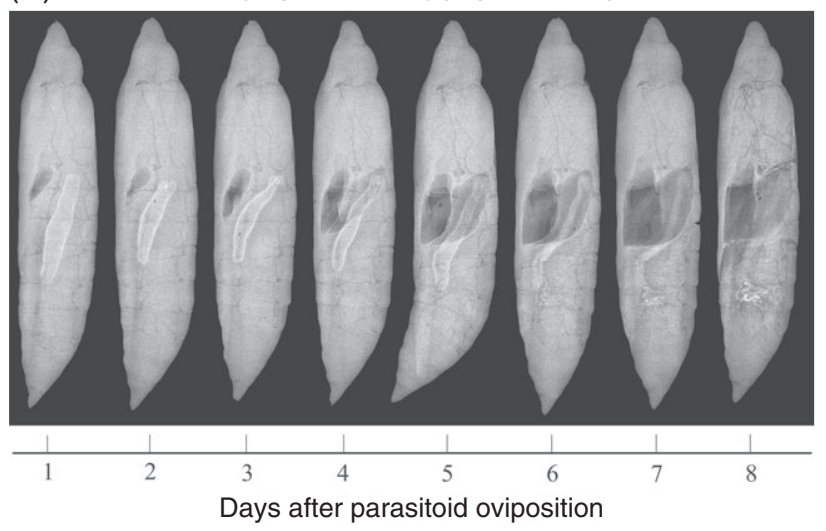

(B) Viable and inviable parasitoid development

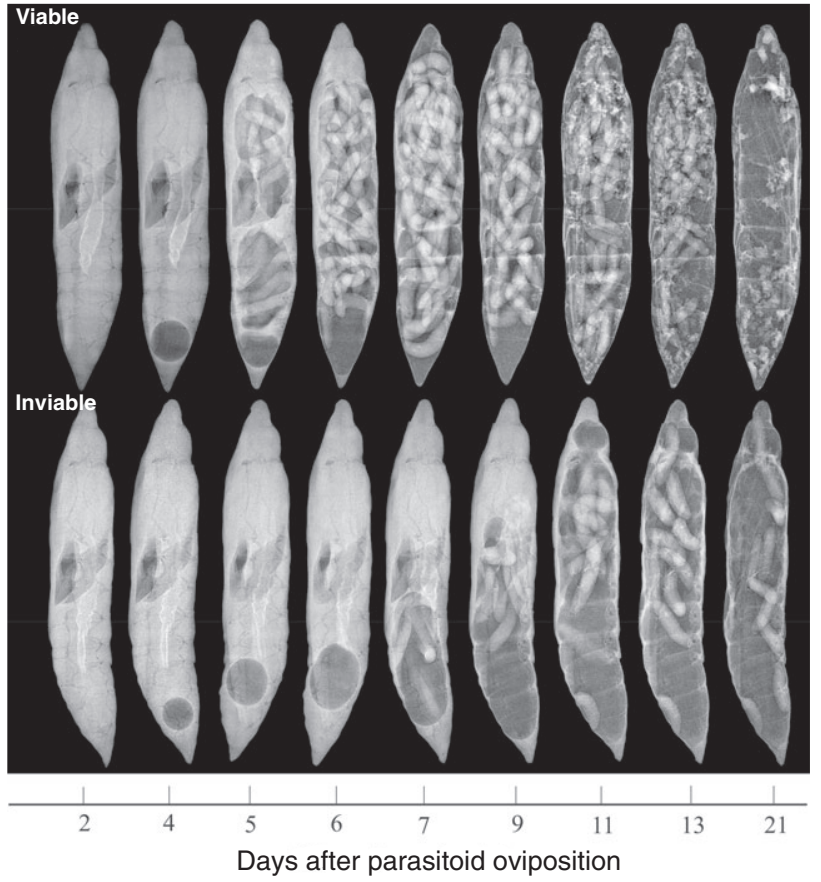

Figure 4. Digitalised X-ray images of the host pupae of the melonworm $D$. hyalinata undergoing normal development until exhibiting the pharate adult stage (A), superparasitised by $P$. elaeisis with parasitoids fully completing their development and starting to emerge as adults (B), and with inviable parasitoids undergoing encapsulation (B).

influenced by the level of superparasitism, female emergence is the key determinant of larval fitness. Indeed, the peak of female emergence observed with three ovipositions per pupa was translated into a peak and thus an optimum larval fitness curve at a similar level of superparasitism, an expected outcome of a scramble process of competition. ${ }^{6,18}$

The outcome reported above is consistent with a scramble process of competition, but indirectly inferred. X-ray imaging allows larval development within the host pupa to be followed, and thus the occurrence of direct aggressive interference or larval accommodation to be recognised. The larvae of P. elaeisis did not exhibit aggressive interference with one another, but spaced themselves within the host pupa, allowing accommodation and resource sharing, expected among endoparasitoids, ${ }^{21}$ without any evidence of infanticide (by the adult female) or siblicide (among larvae), with an apparent slower development 
(A)

Total haemocyte count
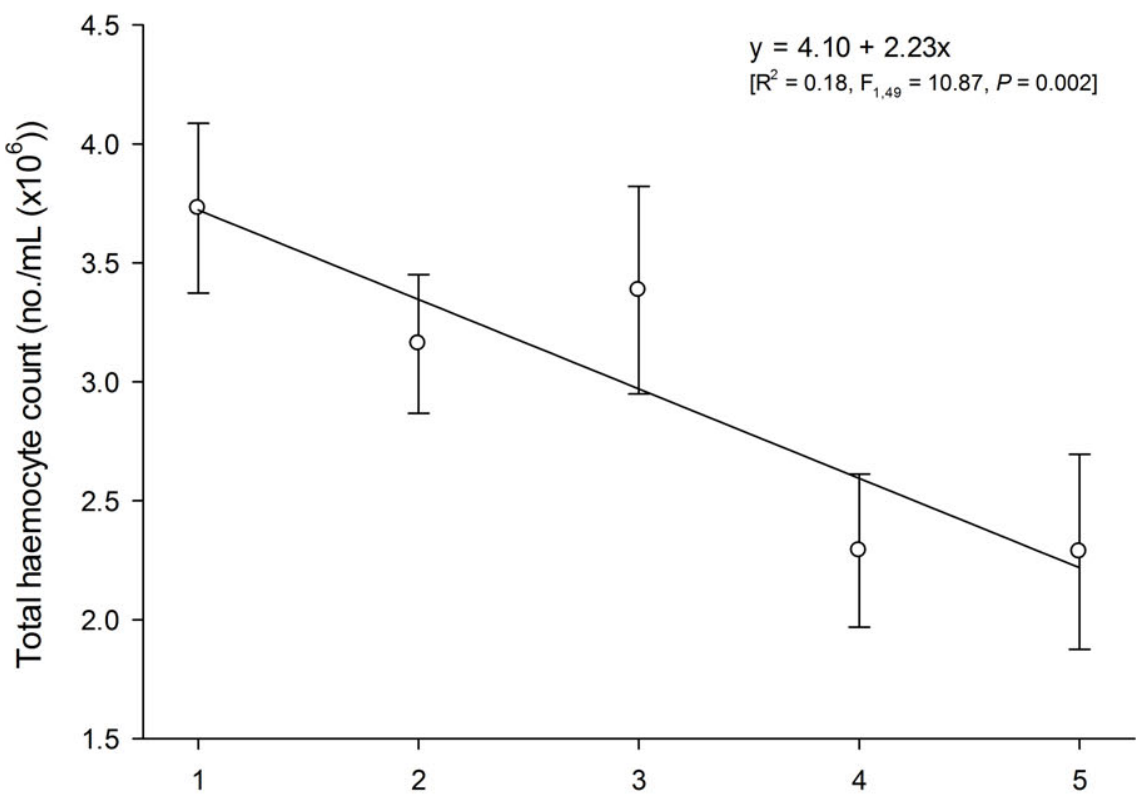

Parasitoid oviposition (no./host pupa)

(B)

Type-specific haemocyte contribution

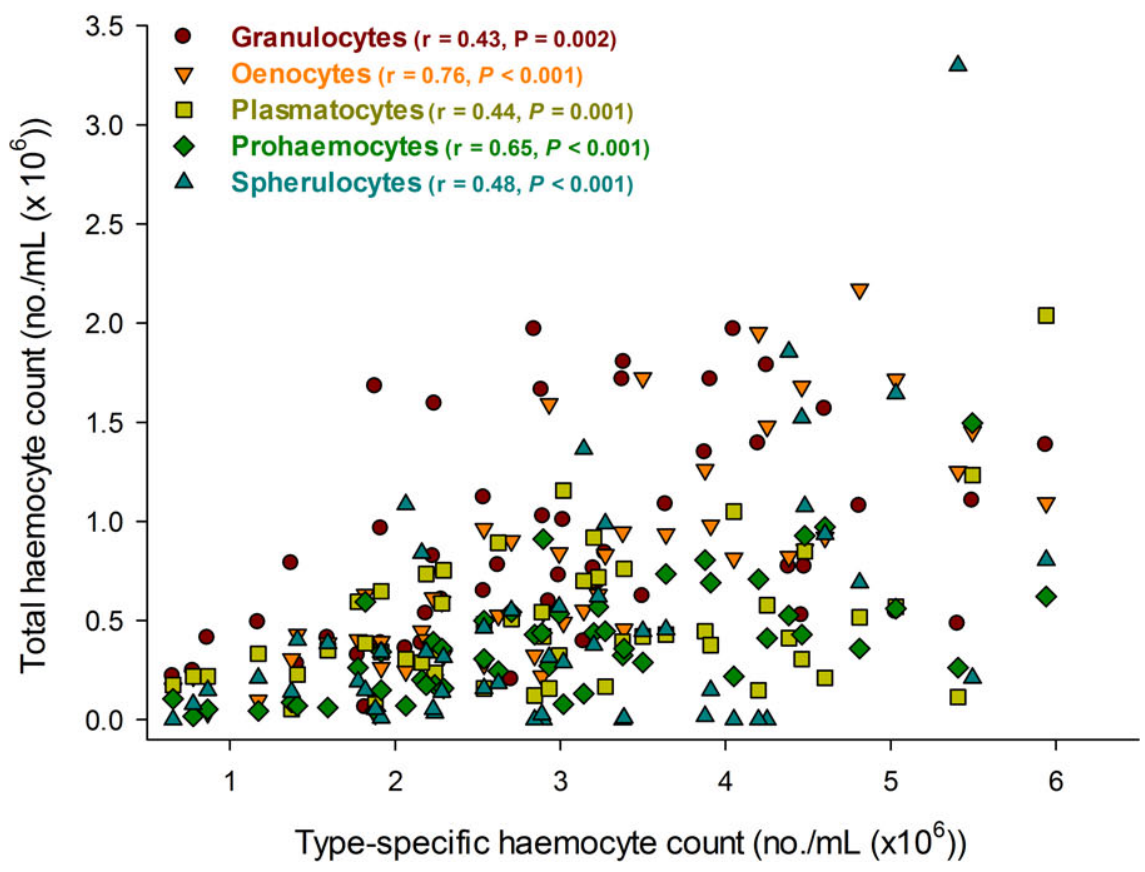

Figure 5. Total haemocyte counts (A) and relationship between total haemocyte counts and counts of each haemocyte type (B) from parasitised (and superparasitised) pupae of the melonworm $D$. hyalinata. Each symbol represents the observed values ( $\mathrm{A}$ : means $\pm \mathrm{SEM}$; $\mathrm{B}$ : individual non-averaged values) of haemocyte counts.

under low superparasitism. Infanticide and siblicide are strategies that allegedly favour superparasitism, ${ }^{11,24-26}$ but here we demonstrated that superparasitism may take place without them. These reported findings provide further and direct evidence of a scramble type of competition among parasitoid larvae within the host pupa. Such an outcome and process, though, may differ if the superparasitic egg clutches are from different conspecific females rather than from the same female (i.e. self-superparasitism), as explored in our study. However, previous findings by Andrade et al. ${ }^{22}$ suggest that the outcome and process are likely the same for P. elaeisis.

High levels of oviposition (at least four per host pupa) seem to compromise resource acquisition by the developing parasitoid larvae, thus reducing their individual body mass and longevity, 
Table 1. Canonical pairs and canonical loadings of a (partial) canonical correlation between total haemocytes and specific haemocyte types, induced by parasitism of $P$. elaeisis in pupae of $D$. hyalinata (the main contributors are indicated in bold)

\begin{tabular}{llc|} 
& \multicolumn{2}{c|}{ Canonical pair } \\
\cline { 2 - 3 } Traits & Coefficient & Correlation \\
\hline First set of traits & & \\
Total haemocytes (number $\left.\mathrm{mL}^{-1}\right)\left(\times 10^{6}\right)$ & 1.00 & $\mathbf{1 . 0 0}$ \\
Second set of traits & & \\
Granulocytes (number $\left.\mathrm{mL}^{-1}\right)\left(\times 10^{6}\right)$ & $\mathbf{0 . 4 1}$ & 0.43 \\
Oenocytes (number $\left.\mathrm{mL}^{-1}\right)\left(\times 10^{6}\right)$ & $\mathbf{0 . 4 1}$ & $\mathbf{0 . 7 6}$ \\
Plasmatocytes $\left(\right.$ number $\left.\mathrm{mL}^{-1}\right)\left(\times 10^{6}\right)$ & 0.28 & 0.44 \\
Prohaemocytes $\left(\right.$ number $\left.\mathrm{mL}^{-1}\right)\left(\times 10^{6}\right)$ & 0.23 & $\mathbf{0 . 6 5}$ \\
Spherulocytes (number $\left.\mathrm{mL}^{-1}\right)\left(\times 10^{6}\right)$ & $\mathbf{0 . 4 8}$ & 0.48 \\
$r$ & 0.99 & \\
$F_{\text {appr }}$ & $\infty$ & \\
$\mathrm{df}_{\text {num/den }}$ & $5 / 45$ & \\
$P$ & $<0.0001$ & \\
\hline
\end{tabular}

as reported on other parasitoid species. ${ }^{43-46}$ In contrast, low levels of oviposition (i.e. no more than two per host pupa) seem to favour longer development and individual parasitoid longevity, but with suboptimal resource use and lower progeny yield per host. Although the level of superparasitism may sometimes affect the sex ratio, ${ }^{20,28,47,48}$ this did not take place with melonworm pupae and $P$. elaeisis. Thus, an optimum parasitoid progeny outcome of $P$. elaeisis in pupae of melonworm was apparent at three ovipositions per host pupa, but besides of an optimum resource use within the level of superparasitism, such an outcome is dependent on the host immune response, particularly its cellular or haemocyte-mediated response.

The encapsulation activity of parasitised melonworm pupae was directly recorded by X-ray imaging progressing with time and leading to inviability of parasitoid larvae. Such a response was particularly strong with a single parasitoid egg clutch, and thus without superparasitism. Superparasitism compromised the inviability of parasitoid larvae, and higher levels of superparasitism further compromised not only haemocyte counts but also both encapsulation and melanisation response. Such effects on haemocyte counts and encapsulation were reported earlier, ${ }^{22}$ but the former encompassed counts of all five haemocyte types observed in the melonworm immune reponse, with particularly higher contributions from oenocytes and prohaemocytes. Although granulocytes and plasmatocytes are reported as the main haemocytes in lepidopteran immune response, ${ }^{24-26,40}$ melonworm pupae exhibit a more even count of the different types of haemocyte, with granulocyte counts prevailing only in parasitised, but not superparasitised, pupae.

Plasmatocytes are important in encapsulation, while granulocytes are usually associated with phagocytic activity in Lepidoptera. ${ }^{24,25,40}$ Thus, plasmatocyte counts should have more influence on encapsulation response in the melonworm pupa against $P$. elaeisis, but the prohaemocyte response was even higher, which is still consistent with expectations as this type of haemocyte is a precursor of the others, ${ }^{40}$ including plasmatocytes and oenocytes. Oenocyte response to increased superparasitism was the strongest and was closely related to total haemocyte response, declining with increasing number of parasitoid ovipositions. As oenocytes are involved in melanisation during
(A) Nylon implants
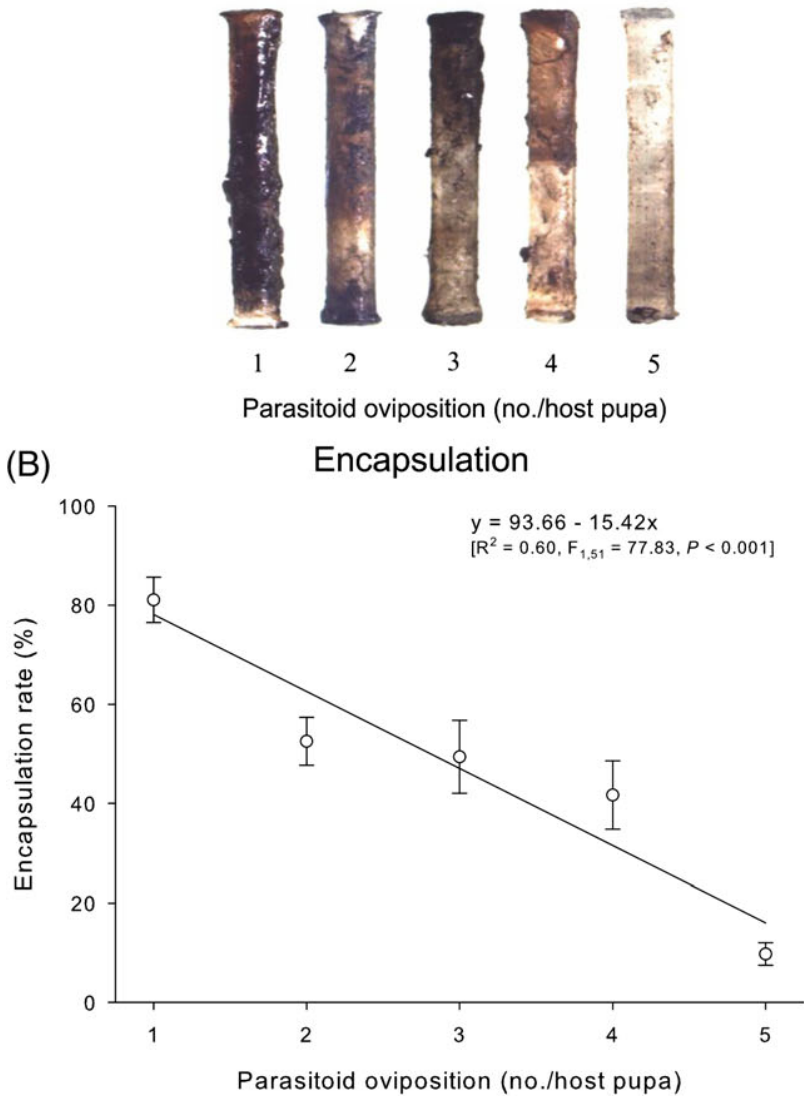

(C) Melanization

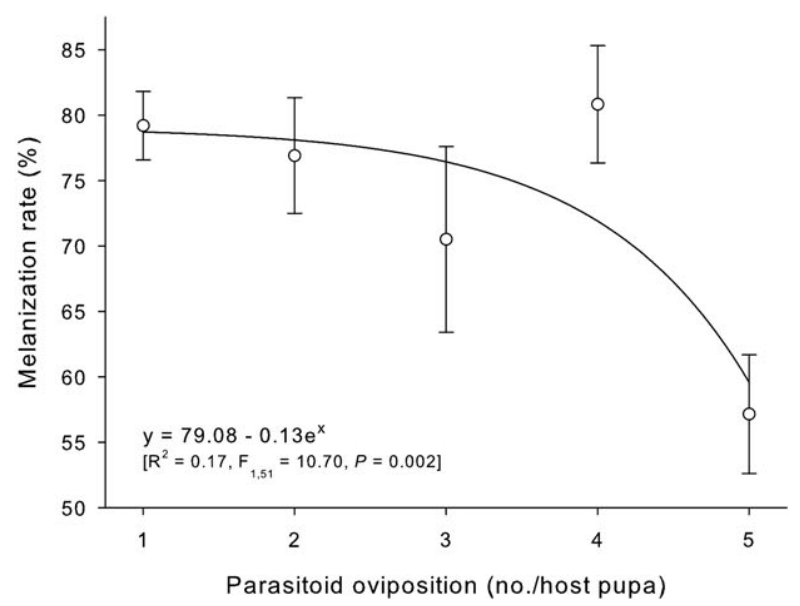

Figure 6. Implanted nylon filaments (A) and rates of encapsulation (B) and melanisation $(C)$ recorded from pupae of the melonworm $D$. hyalinata subjected to increasing levels of superparasitism by P. elaeisis. Each symbol in (B) and (C) represents the mean observed values, and the vertical bars indicate the standard error of the respective means.

encapsulation owing to their production of phenoloxidases, ${ }^{40}$ the response is consistent with the patterns of immune response observed, particularly encapsulation and melanisation. The functions of spherulocytes are not well known, but their response followed those of the other haemocyte types, with the total haemocyte count declining with increased superparasitism in pupae of the melonworm. 
Higher parasitoid oviposition favoured exhaustion of the host immune response in melonworm pupae, likely owing to the injection of symbiotic virus, teratocytes and/or ovary proteins from the parasitoids into the host, as reported in other parasitoid species. ${ }^{21,49-51}$ Haemocyte exhaustion compromised encapsulation activity (i.e. the binding of haemocytes forming a sheath around the targeted invader), a relationship also observed in our study, as in different parasitoids. ${ }^{11,21,25}$ Melanisation, resulting from phenoloxidase activity in the encapsulated invader, was also compromised with superparasitism, as would be expected based on previous findings. ${ }^{22,25}$ Although the parasitised host was unable to survive parasitism by even a single parasitoid egg clutch, parasitoid inviability was higher in such conditions, while a higher number of egg clutches favoured parasitoid yield, in addition to their fitness, benefiting their role as biocontrol agents.

Altogether, increased superparasitism by P. elaeisis compromises the host immune response, as reflected by a reduction in haemocyte counts, encapsulation and melanisation. Therefore, such a trend, combined with an optimum parasitoid larval fitness at three ovipositions per host, indicated that host resource use is optimum at this level of superparasitism, allowing a peak in parasitoid progeny yield without compromising progeny body mass and thus its subsequent performance. In summary, optimum parasitoid yield is due to the scramble process of larval competition with maximum host resource sharing and depletion of the host immune response. Host pupal survival is prevented with a single oviposition by P. elaeisis, but maximum parasitoid yield is relevant for their mass rearing and the optimum release rate as a biological control agent to be considered in insect pest management programmes. Eventual mass rearing of $P$. elaeisis should consider the optimum clutch size per host pupa to maximise parasitoid yield and quality production, which also needs to be considered when estimating the rate of field release of the parasitoid for purposes of biological control.

\section{ACKNOWLEDGEMENTS}

The financial support provided by the National Council of Scientific and Technological Development (CNPq), the CAPES Foundation and the Minas Gerais State Foundations of Research Aid (FAPEMIG) is greatly appreciated.

\section{REFERENCES}

1 Nicholson AJ, An outline of the dynamics of animal populations. Aust $J$ Zool 2:9-65 (1954).

2 Varley GC, Gradwell GR and Hassell MP, Insect Population Ecology. Blackwell, Oxford, UK (1973).

3 Smith RH, Genetic and phenotypic aspects of life-history evolution in animals. Adv Ecol Res 21:63-120 (1991).

4 Bakker K, An analysis of factors which determine success in competition for food among larvae of Drosophila melanogaster. Arch Néerland Zöol 2:250-281 (1961).

5 De Jong G, A model of competition for food. I. Frequency-dependent viabilities. Am Nat 110:1013-1027 (1976).

6 Smith RH and Lessells CM, Oviposition, ovicide and larval competition in granivorous insects, in Behavioural Ecology: Ecological Consequences of Adaptive Behaviour, ed by Sibly RM and Smith RH. Blackwell, London, UK, pp. 423-448 (1985).

7 Kaser JM and Ode PJ, Hidden risks and benefits of natural enemy-mediated indirect effects. Curr Opin Insect Sci 14:105-111 (2016).

8 Cusumano A, Peri E and Colazza S, Interspecific competition/facilitation among insect parasitoids. Curr Opin Insect Sci 14:12-16 (2016).
9 Godfray HCJ, Four decades of parasitoid science. Entomol Exp Applic 159:135-146 (2016).

10 van Alphen JJM and Visser ME, Superparasitism as an adaptive strategy for insect parasitoids. Annu Rev Entomol 33:59-79 (1990).

11 Tena A, Kapranas A, Garcia-Marí F and Luck RF, Host discrimination, superparasitism and infanticide by a gregarious endoparasitoid. Anim Behav 76:789-799 (2008).

12 White JA and Andow DA, Benefits of self-superparasitism in a polyembryonic parasitoid. Biol Control 46:133-139 (2008).

13 Ruschioni S, van Loon JJA, Smid HM and van Lenteren JC, Insects can count: sensory basis of host discrimination in parasitoid wasps revealed. PLoS ONE 10:e0138045 (2015).

14 Vinson SB and Hegazi EM, A possible mechanism for the physiological suppression of conspecific eggs and larvae following superparasitism by solitary endoparasitoids. J Insect Physiol 44:703-712 (1998).

15 Zappalà L and Hoy MA, Reproductive strategies and parasitization behavior of Ageniaspis citricola, a parasitoid of the citrus leafminer Phyllocnistis citrella. Entomol Exp Applic 113:135-143 (2004).

16 Guedes RNC, Smith RH and Guedes NMP, Host suitability, respiration rate and the outcome of larval competition in strains of the cowpea weevil, Callosobruchus maculatus. Physiol Entomol 28:298-305 (2003).

17 Guedes RNC, Guedes NMP and Smith RH, Larval competition within seeds: from the behaviour process to the ecological outcome in the seed beetle Callosobruchus maculatus. Aust Ecol 32:697-707 (2007).

18 Guedes NMP, Guedes RNC, Campbell JF and Throne JE, Contest behaviour of maize weevil larvae when competing within seeds. Anim Behav 79:281-289 (2010).

19 Godfray HCJ, Parasitoids: Behavioral and Evolutionary Ecology. Princeton University, Princeton, NJ (1994).

20 Dorn S and Beckage NE, Superparasitism in gregarious hymenopteran parasitoids: ecological, behavioural and physiological perspectives. Physiol Entomol 32:199-211 (2007).

21 Harvey JA, Poelman EH and Tanaka T, Intrinsic inter- and intraspecific competition in parasitoid wasps. Annu Rev Entomol 58:333-351 (2013).

22 Andrade GS, Serrão JE, Zanuncio JC, Zanuncio TV, Leite GLD and Polanczyk RA, Immunity of an alternative host can be overcome by higher densities of its parasitoids Palmistichus elaeisis and Trichospilus diatraeae. PLoS ONE 5:e13231 (2010).

23 Andrade GS, Sousa AH, Santos JC, Gama FC, Serrão JE and Zanuncio JC, Oogenesis pattern and type of ovariole of the parasitoid Palmistichus elaeisis (Hymenoptera: Eulophidae). An Acad Bras Ciênc 84:767-774 (2012).

24 Lavine MD and Strand MR, Insect hemocytes and their role in immunity. Insect Biochem Mol Biol 32:1295-1309 (2002).

25 Strand MR, The insect cellular immune response. Insect Sci 15:1-14 (2008).

26 Stoepler TM, Castillo JC, Lill JT and Eleftherianos I, Hemocyte density increases with developmental stage in an immune-challenged forest caterpillar. PLOS ONE 8:e70978 (2013).

27 Ibrahim AMA and Kim Y, Parasitism by Cotesia plutellae alters the hemocyte population and immunological function of the diamondback moth, Plutella xylostella. J Insect Behav 52:943-950 (2006).

$28 \mathrm{Gu} \mathrm{H}$, Wang Q and Dorn S, Superparasitism in Cotesia glomerata: response of hosts and consequences for parasitoids. Ecol Entomol 28:422-431 (2003).

29 Silva-Torres CSA, Filho ITR, Torres JB and Barros R, Superparasitism and host size effects in Oomyzus sokolowskii, a parasitoid of diamondback moth. Entomol Exp Applic 133:65-73 (2009).

30 van Nouhuys $\mathrm{S}$ and Punju E, Coexistence of competing parasitoids: which is the fugitive and where does it hide? Oikos 119:61-70 (2010).

31 Prado SG and Frank S, Optimal foraging by an aphid parasitoid affects. Ecol Entomol 39:236-244 (2014).

32 Pereira FF, Zanuncio TV, Zanuncio JC, Pratissoli D and Tavares MT, Species of Lepidoptera defoliators of eucalypt as new hosts for the polyphagous parasitoid Palmistichus elaeisis (Hymenoptera: Eulophidae). Braz Arch Biol Technol 51:259-262 (2008).

33 Chichera RA, Pereira FF, Kassab SO, Barbosa RH, Pastori PL and Rossoni C, Capacidade de busca e reprodução de Trichospilus diatraeae e Palmistichus elaeisis (Hymenoptera: Crambidae). Interciências 37:1-5 (2012). 
34 Guedes RNC and Smith RH, Competition strategies and correlated selection on responses to polyandry in the seed beetle Callosobruchus maculatus. Physiol Entomol 33:372-381 (2008).

35 Greene GL, Leppla NC and Dickerson WA, Velvetbean caterpillar: a rearing procedure and artificial diet. J Econ Entomol 69:487-488 (1976).

36 Pratissoli D, Polanczyk RA, Holtz AM, Tamanhoni T, Celestino FN and Borges Filho RC, Influence of nutritional substrates on the development of Diaphania hyalinata L. (Lepidoptera: Crambidae). Neotrop Entomol 37:361 - 364 (2008).

37 Zanuncio JC, Pereira FF, Jaques GC, Tavares MT and Serrão JE, Tenebrio molitor Linnaeus (Coleoptera: Tenebrionidae), a new alternative host to rear the pupae parasitoid Palmisticus elaeisis Delvare and LaSalle (Hymenoptera: Eulophidae). Coleopt Bull 62:64-66 (2008).

38 Delvare $G$ and Lasalle JA, New genus of Tetrastichinae (Hymenoptera: Eulophidae) from the neotropical region, with the description of a new species parasitica on key pests of oil palm. J Nat Hist 27:435-444 (1993).

39 Wei K, Tang Y-L, Wang X-Y, Cao L-M and Yang Z-Q, The developmental strategies and related profitability of an idiobiont ectoparasitoid Sclerodermus pupariae. Ecol Entomol 39:101 - 108 (2014).

40 Ribeiro $C$ and Brehélin $M$, Insect haemocytes: what type of cell is that? J Insect Physiol 52:417-429 (2006).

41 Diamond SE and Kingsolver JG, Host plant quality, selection history and trade-offs shape the immune responses of Manduca sexta. Proc R Soc B 278:289-297 (2010).

42 Silva IM, Zanuncio TV, Pereira JMM, Wilcken CF, Pereira FF, Serrão JE et al., Density of Trichospilus diatraeae (Hymenoptera: Eulophidae) parasitizing Diaphania hyalinata (Lepidoptera: Crambidae) pupae. Ann Entomol Soc Am 107:826-831 (2014).
43 Alleyne M and Beckage NE, Parasitism-induced effects on host growth and metabolic efficiency in tobacco hornworm larvae by Cotesia congregate. J Insect Physiol 43:407-424 (1997).

44 Zaviezo T and Mills N, Factors influencing the evolution of clutch size in a gregarious insect parasitoid. J Anim Ecol 69:1047-1057 (2000).

45 Jaramillo J, Borgemeister $C$ and Setamou M, Field superparasitism by Phymastichus coffea, a parasitoid of adult coffee berry borer, Hypothenemus hampei. Entomol Exp Applic 119:231-237 (2006).

46 Keinan Y, Kishinevsky M, Segoli M and Keasar T, Repeated probing of hosts: an important component of superparasitism. Behav Ecol 23:1263-1268 (2012).

47 Suzuki Y, Tsuji $\mathrm{H}$ and Sasakawa M, Sex allocation and effects of superparasitism on secondary sex ratios in the gregarious parasitoid, Trichogramma chilonis (Hymenoptera: Trichogrammatidae). Anim Behav 32:478-484 (1984).

48 van Dijken MJ and Waage JK, Self and conspecific superparasitism by the egg parasitoid Trichogramma evanescens. Entomol Exp Applic 43:183-192 (1987).

49 Sagarra LA, Peterkin DD, Vincent C and Stewart RK, Immune response of the hibiscus mealybug, Maconellicoccus hirsutus Green (Homoptera: Pseudococcidae), to oviposition of the parasitoid Anagyrus kamali Moursi (Hymenoptera: Encyrtidae). J Insect Physiol 46:647-653 (2000).

50 Glatz RV, Asgari S and Schmidt O, Evolution of polydnaviruses as insect immune suppressors. Trends Microbiol 12:545-554 (2004).

51 Zhang Q-Q, Huang J, Zhu J-Y and Ye G-Y, Parasitism of Pieris rapae (Lepidoptera: Pieridae) by the endoparasitic wasp Pteromalus puparum (Hymenoptera: Pteromalidae): effects of parasitism on differential hemocyte counts, micro- and ultra-structures of host hemocytes. Insect Sci 19:485-497 (2012). 